\title{
Aeromagnetic anomaly images of Vulcano and Southern Lipari Islands (Aeolian Archipelago, Italy)
}

\author{
Robert Supper $\left({ }^{1}\right)$, Riccardo De Ritis $\left({ }^{2}\right)$, Klaus Motschka $\left({ }^{1}\right)$ and Massimo Chiappini $\left({ }^{2}\right)$ \\ $\left.{ }^{1}\right)$ Geological Survey of Austria and University of Vienna, Vienna, Austria \\ ${ }^{2}{ }^{2}$ Istituto Nazionale di Geofisica e Vulcanologia, Roma, Italy
}

\begin{abstract}
Newly acquired high-resolution, low-altitude aeromagnetic data over Vulcano Island and Southwestern Lipari in the Southern Tyrrhenian Sea resolve the major volcanic features in the area associated with the past and present activity. The magnetic character changes in amplitude and frequency from south-east to north-west. The Primordial Vulcano, the Lentia Complex, the Piano Caldera units, the Fossa Caldera deposits, and the currently active La Fossa cone and Vulcanello represent the main volcanic phases on Vulcano Island. They show a distinct magnetic anomaly pattern, whereas prior to this survey, no magnetic signatures of these features were found.
\end{abstract}

Key words aeromagnetic data - magnetic anomalies - geomagnetism - Vulcano

\section{Introduction}

The Aeolian Arc, in the Southern Tyrrhenian Sea, is characterized by active volcanism, which may threaten population safety and activities. An international activity has been launched, aimed at investigating these highly hazardous areas by means of integrated multidisciplinary geophysical studies. The purpose of magnetic surveying is, in fact, to identify the shallow geological components and the crustal contribution of the Earth's magnetic field. When devoted to the definition of magnetic fields, likely generated by spatial variations in the magnetization of crustal rocks, magnetic anomaly maps are produced to show this contribution. By means of the survey described in

Mailing address: Dr. Riccardo De Ritis, Istituto Nazionale di Geofisica e Vulcanologia, Via di Vigna Murata 605, 00143 Roma, Italy; e-mail: deritis@ingv.it the present paper we highlight the lateral variation of magnetizations of the shallow crustal rocks, computing the magnetic anomaly field.

An initial approach was conducted in cooperation between the Geological Survey of Austria and the Istituto Nazionale di Geofisica e Vulcanologia of Rome, acquiring high-resolution airborne geophysical data over Vulcano Island. Vulcano is located in the southern sector of the Aeolian volcanic district, and lies along a NNW-SSE graben-like structure, approximately parallel to the strike-slip «Tindari-Letoianni» Fault (Barberi et al., 1994). The airborne survey, conducted by means of a locally hired Squirrel AS-350 helicopter, also partially covered the western side and the submerged flanks of Lipari Island. The aim of the present paper is to image the crustal structure of the area by means of magnetic anomaly data, to characterize the magnetic sources associated with the various Volcanic cycles.

In addition to aeromagnetic data laser altimetry and gamma ray data were also collected. We focus our attention on processing the magnetic data to develop the anomaly pattern of the surveyed area and perform mathematical analysis and data enhancement. 
The whole Tyrrhenian Sea was previously investigated by means of oceanographic campaigns between 1965 and 1972 (Allan and Morelli, 1971). The cruises acquired bathymetric, gravity and magnetic data. Chiappini et al. (2000) reprocessed the magnetic data set and compiled a regional magnetic anomaly map at sea level.

As far as aeromagnetic data are concerned, previous surveys in the Southern Tyrrhenian Sea were performed by the Italian national oil company (Agip) in the late 1970's. Agip acquired total field magnetic data at an altitude of $4800 \mathrm{ft}(1500 \mathrm{~m})$, and published a grid with an average spacing of $2.5 \mathrm{~km}$ (Agip Spa, 1981).

\section{Acquisition and processing}

The airborne survey covered the entire Vulcano Island and partially the western side and the submerged flanks of Lipari. An opticallypumped magnetometer acquired the total intensity of the Earth's magnetic field at a varying barometric height, which provided a minimum terrain clearance of about $50 \mathrm{~m}$ above the highest peaks. Due to the rugged topographic conditions, however, an average clearance was maintained around $150 \mathrm{~m}$.

The magnetic sensor was towed about $30 \mathrm{~m}$ below the helicopter. The ground-based equipment consisted of a magnetic base station recording the Earth magnetic field variations for the entire duration of the survey flights. The magnetic base station was deployed on the Island, and recorded data at $1 \mathrm{~Hz}$.

The aeromagnetic survey was conducted at $250 \mathrm{~m}$ line spacing with tie lines at an average of $3000 \mathrm{~m}$ apart. Figure 1 shows the distribution of the aeromagnetic profiles, as well as the location of the magnetic base station. The towedbird magnetometer acquired data at $10 \mathrm{~Hz}$. GPS receiver was used for precise survey navigation. Recording of flight altitude was assured by acquisition of laser altimeter data at $0.3 \mathrm{~Hz}$. All magnetic and pseudorange navigation data were recorded on a PC-based data acquisition system on board the helicopter.

Data were de-spiked and each measurement profile was visually inspected. The base station data were used to remove the diurnal variation of the Earth's magnetic field from the aeromagnetic data. The survey was then reduced to a common geomagnetic epoch using the following equation:
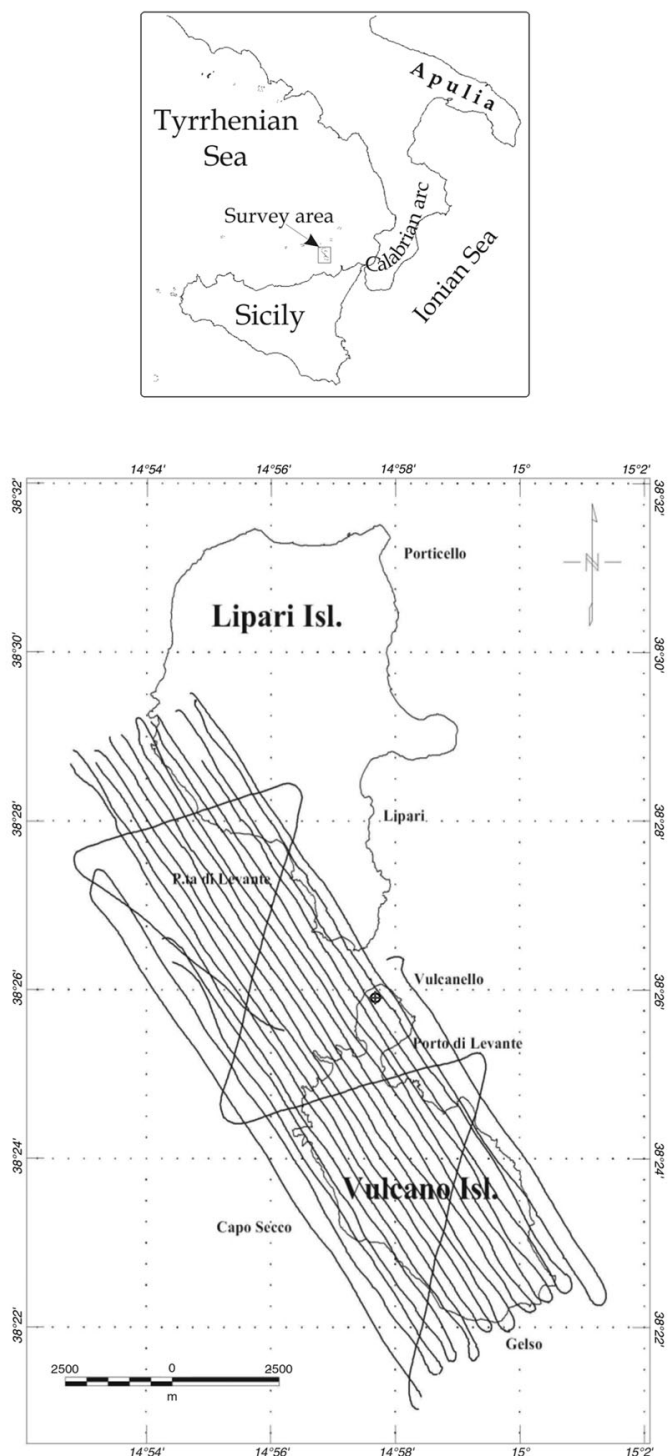

Fig. 1. Distribution of the aeromagnetic profiles over Vulcano Island and the southwestern flank of Lipari. The symbol $\oplus$ indicates the position of the magnetic base station. In the inset, the location of the survey area in the Southern Tyrrhenian Sea is indicated. 


$$
F_{s}^{99.7}=F_{b s}^{99.7}+\left(F_{s}^{t}-F_{b s}^{t}\right)
$$

where $F_{s}^{t}$ is the magnetic field (nT) acquired during the survey at time $t$ at point $s ; F_{b s}^{t}$ is the value observed at the same time $t$ at the base station; $F_{b s}^{99.7}$ is the value at the base station at 1999.7 and $F_{s}^{99.7}$ is the value at the same point $s$ reduced to 1999.7 .

To compute the magnetic anomaly field, data were corrected using the Italian Geomagnetic
Reference Field (ItGRF) (Molina and De Santis, 1987; De Santis et al., 2003). This model, despite having the same spatial gradients as IGRF, is more constrained by the secular variation observed at L'Aquila geomagnetic observatory.

Crossover analysis between profiles and tie lines showed a few leveling errors, which were statistically adjusted in a similar fashion as described in Chiappini et al. (2000). A $60 \mathrm{~m}$ cell grid then was produced as shown in fig. 2,

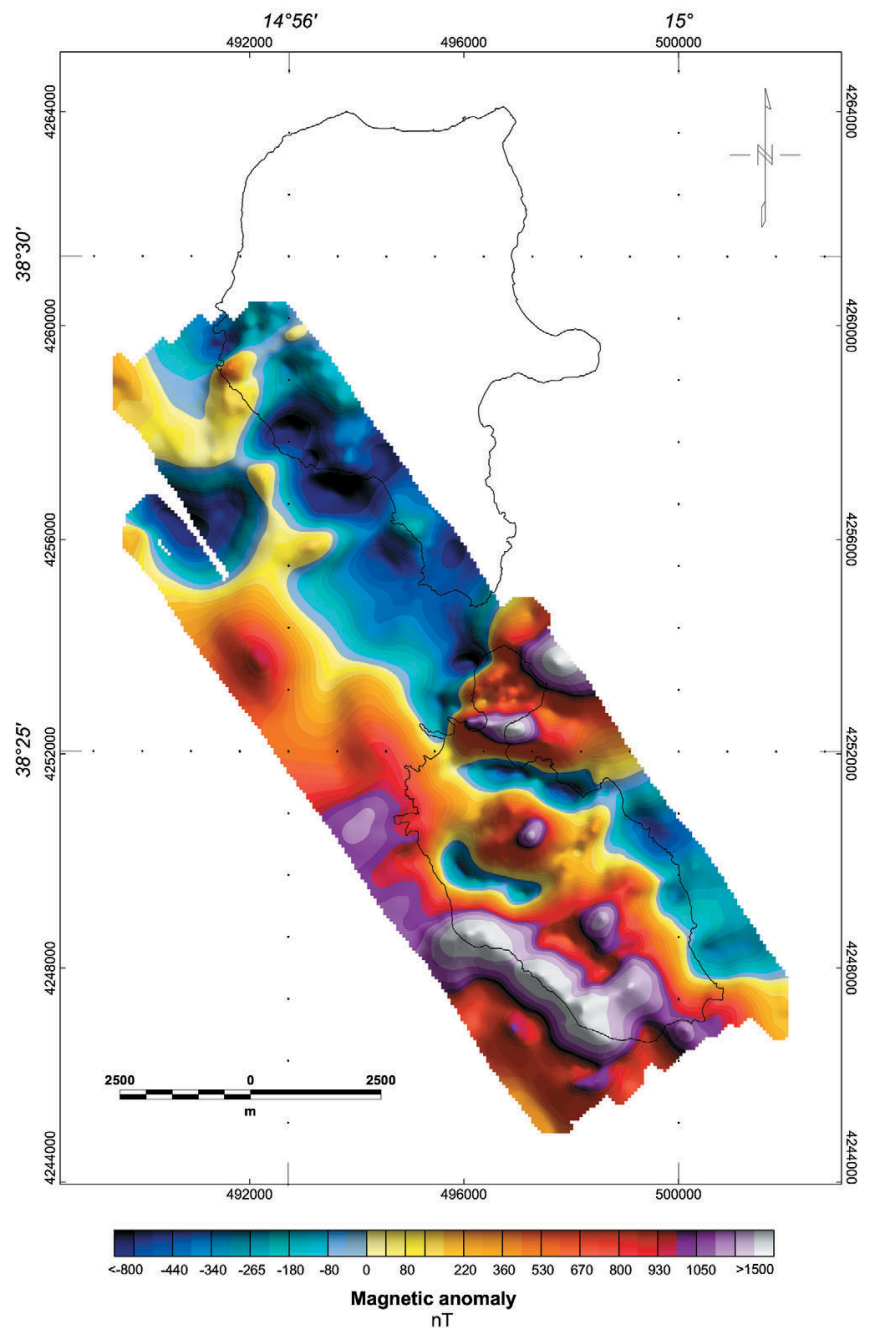

Fig. 2. Shaded-relief aeromagnetic anomaly map of Vulcano and Southwestern Lipari. 
where we applied shading algorithms to artificially illuminate the anomalies, emphasizing those that are perpendicular or oblique to the direction of illumination.

\section{Aeromagnetic anomalies}

The magnetic anomaly pattern of Vulcano and Southeastern Lipari shows both short and long wavelength anomalies. While the former are associated with variations of magnetization of shallow rocks, the latter may likely reflect the regional character of tectonic features or may be caused by bodies deeper than the outcropping volcanic structure. Superimposing the magnetic anomaly grid to the digital elevation model of Lipari and Vulcano Islands and the surrounding bathymetry, facilitates the identification of magnetic anomaly features in relation

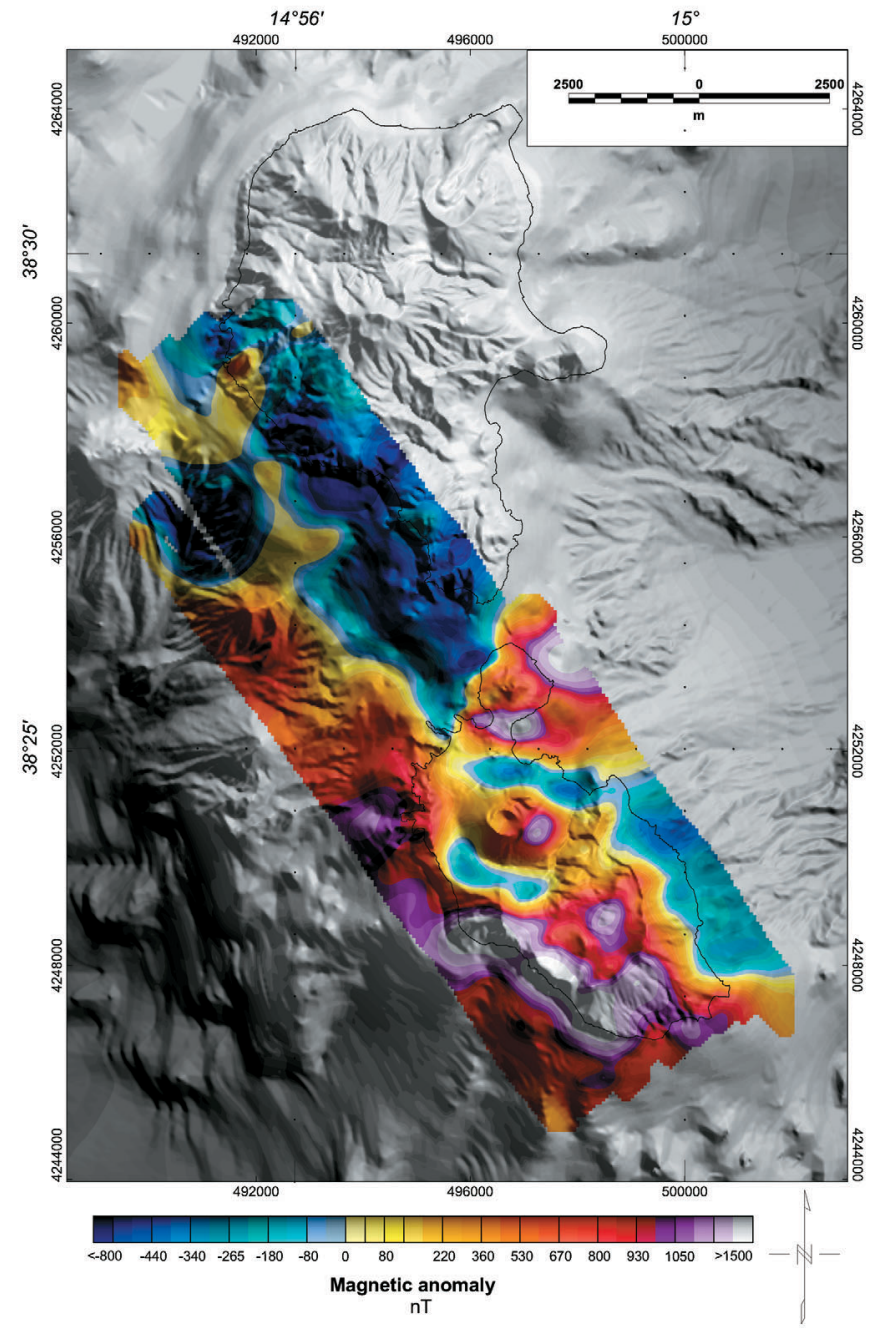

Fig. 3. Aeromagnetic anomaly field superimposed on the shaded-relief image of the digital elevation model and surrounding bathymetry. 


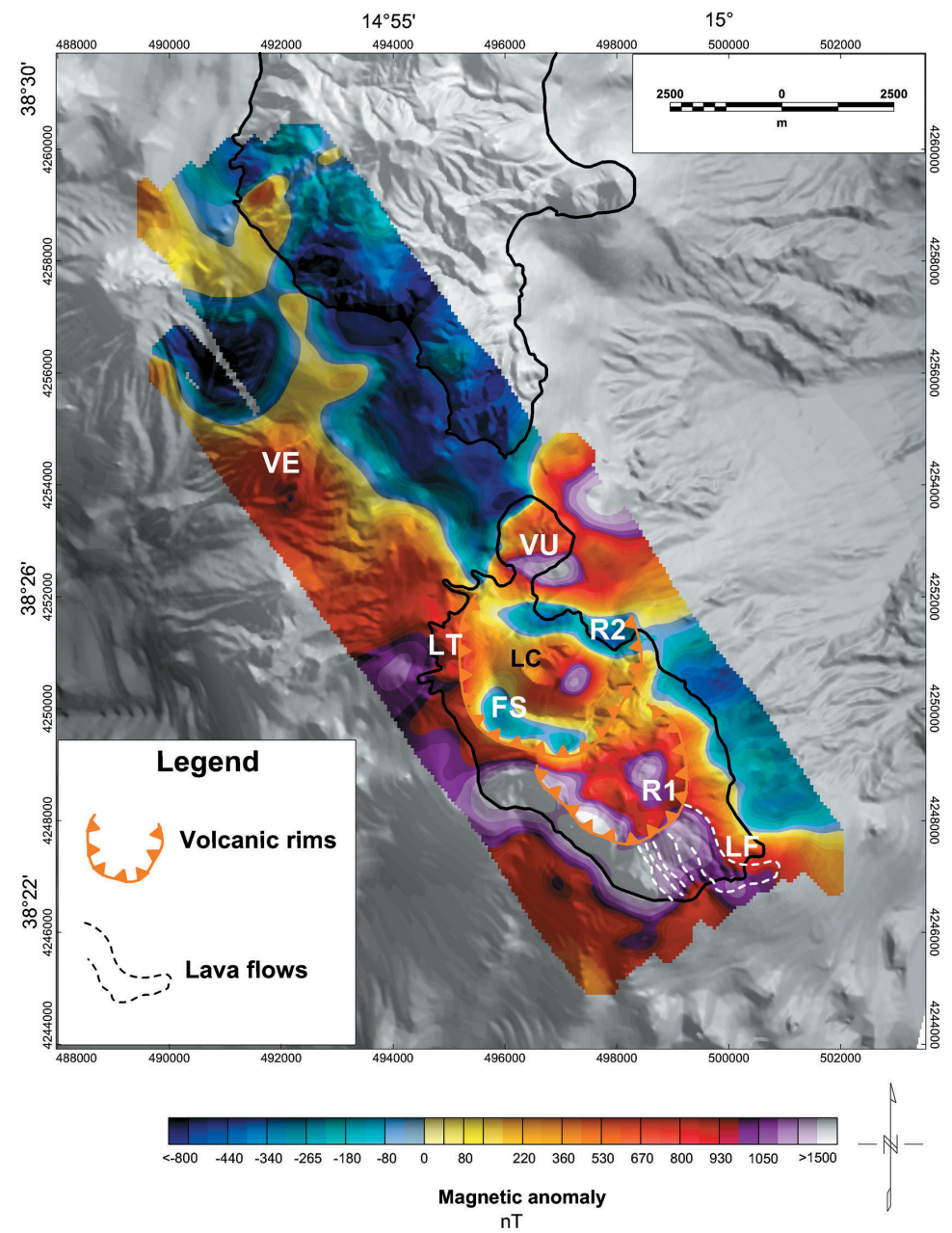

Fig. 4. Major geomorphologic and volcanic features identified by the magnetic anomaly field. VE - off shore volcanic edifice; LF - sequence of lava flows; R1 - Piano Caldera volcanic rim; FS - sub-circular negative magnetic anomaly; LC - La Fossa Cone; R2 - La Fossa Caldera volcanic rim; LT - Lentia Complex; VU - Vulcanello.

to possible shallow sources. This is clearly imaged in fig. 3. For example, in the off shore sector, northwest of Vulcano, a round positive anomaly is well resolved (VE in fig. 4). It seems to be associated with an isolated relief identified by Gabbianelli et al. (1991) by means of seismic profiles, and interpreted as eccentric volcanic edifices, and clearly identified with the digital elevation model.
The southwestern flank of Vulcano is characterized by a high amplitude, NW-SE trending linear positive anomaly, which runs approximately parallel to the coast line. This anomaly also borders the southwestern margin of the «Primordial Vulcano» as shown in fig. 4 and in the geological map in fig. 5. This truncated composite cone forms the oldest (120 to 100 kyr) part of the Island. 


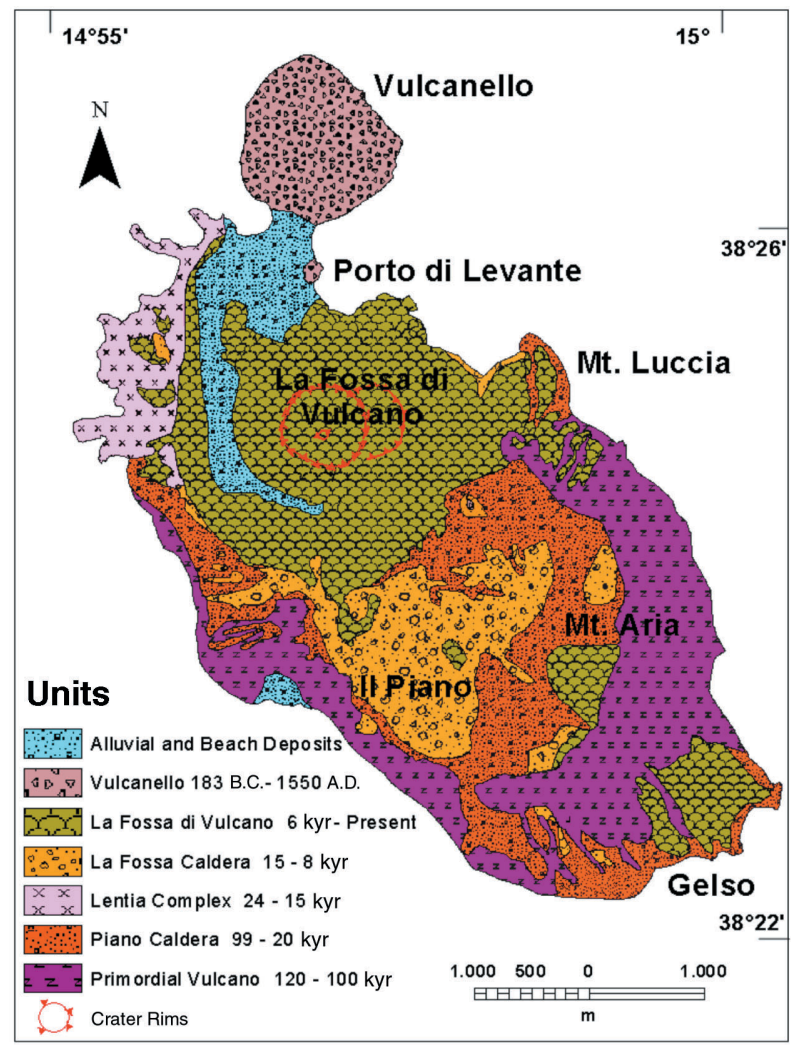

Fig. 5. Geological map of Vulcano Island, modified from De Astis et al. (1997), showing the six volcanic units.

Once the primordial volcano collapsed, a subsequent eruption phase which occurred until 20 kyr emplaced the Piano Caldera Units (De Astis et al., 1997). The volcanic rim (indicated with R1 in fig. 4) presents a distinct magnetic signature having its highest amplitude values in the southwestern part. South-east of R1 a remarkable magnetic anomaly feature, labeled LF in fig. 4 and extending in the offshore sector, could be related to a sequence of lava flows not completely outcropping. In the north-western part of the Island, a high-amplitude positive anomaly seems to be associated with the Lentia Complex (LT in fig. 4), which is a remnant of a larger volcanic structure formed between 24 and 15 kyr (fig. 5) (Barberi et al., 1994).

Observe in the area of La Fossa a circular positive anomaly overlapping with the volcanic rim R2 (fig. 4). La Fossa caldera consists of volcanic units erupted between 15 and $8 \mathrm{kyr}$ approximately, being therefore a later volcanic phase (De Astis et al., 1997). Within R2, a lowamplitude, short-wavelength negative anomaly (FS) surrounds a magnetic high, associated with the edifice of La Fossa cone (LC in fig. 4). La Fossa cone is an active volcanic edifice extending $391 \mathrm{~m}$ high, located approximately in a central position with respect to the caldera. Formed during the last $6 \mathrm{kyr}$, the cone produced the last eruption in 1880-1890, as reported by Frazzetta et al. $(1983,1984)$.

The northernmost structure of the Island is called Vulcanello. Indicated in fig. 4 with VU, Vulcanello is a composite lava platform, formed as a new Island in 183 B.C. By means of ash accumulation due to successive eruptions in the 6th 
and 16 th centuries A.D., it was later connected to the main Island. The lava platform is well resolved by the aeromagnetic image with a positive long-wavelength pattern.

Moreover the region extending between the south western side of Lipari and a narrow strip of sea in front of this Island is characterized by extremely low values of the anomaly magnetic field $(-800 \mathrm{nT})$. A possible reason for such anomaly values could be related to a negative part of an induced dipolar field whose positive counterpart would be the high-amplitude anomaly situated west of it. Alternatively these values could be related to remanent magnetization of a body cooled during a reverse-polarity chron. The latter interpretation seems to be far from reality because the Aeolian volcanism took place entirely in the present Brunes chron. It turns out that an extension of the survey in the remaining part of Lipari Island to better understand the presence of this large negative anomaly area is worthwhile.

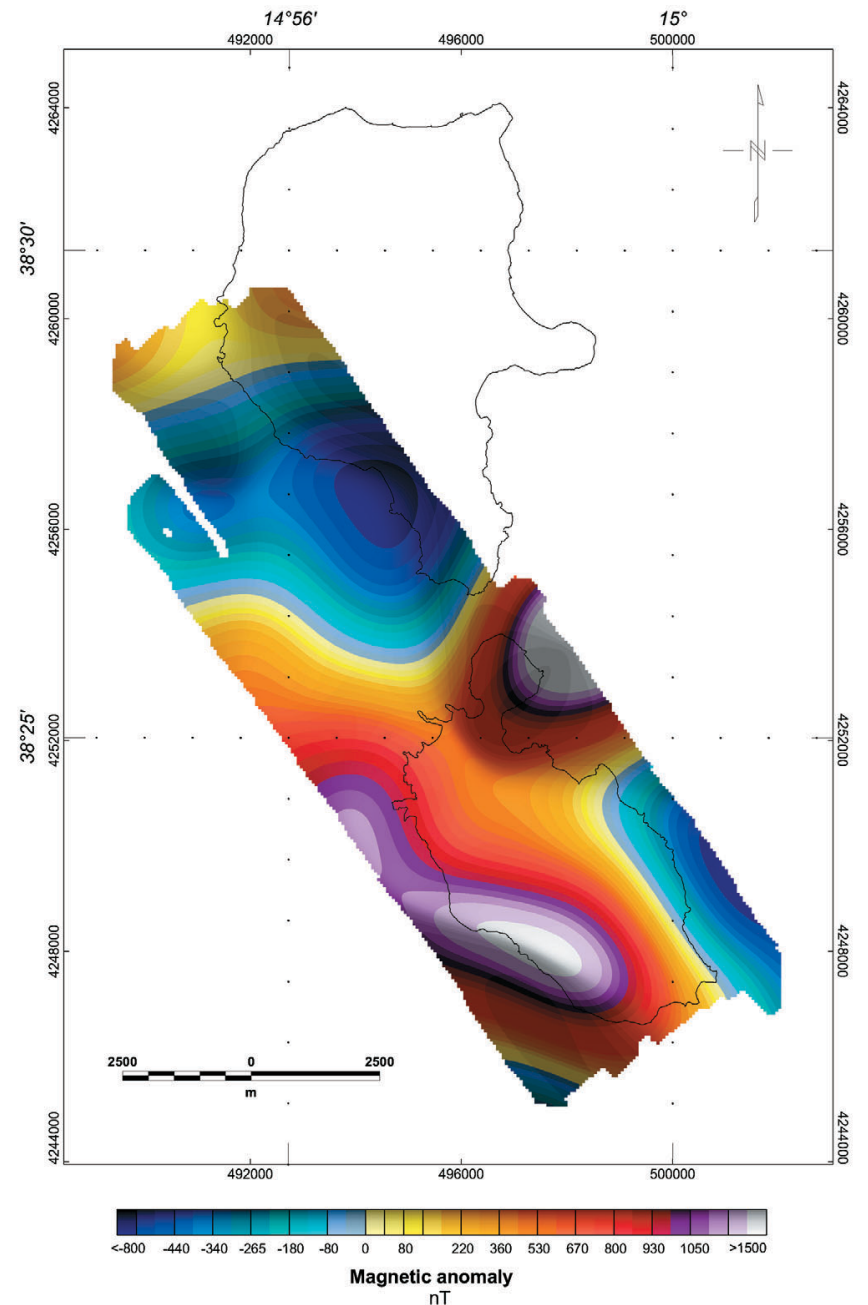

Fig. 6. Upward continued magnetic anomaly map (1500 m). 
As previously mentioned, existing aeromagnetic data in the study area belong to an old survey conducted in the late 1970's by Agip (Agip Spa, 1981). The regional character and the different acquisition altitude of the Agip map do not resolve the volcanic features we identified in detail. We attempted to compare our anomaly field with the Agip data set. Observe in fig. 6 the upward continued map to $1500 \mathrm{~m}$. This image clearly shows long-wavelength features, as well as a remarkable similarity with the Agip map (Barberi et al., 1994).

\section{Conclusions}

A high-resolution shaded relief total intensity, magnetic anomaly map was obtained after a helicopter-borne aeromagnetic survey over Vulcano Island. The anomaly field is characterized by a wide range of amplitudes and wavelengths. The main stages of volcanic activity in the area are investigated by the new data set: the Primordial Vulcano, the Piano Caldera units older than $20 \mathrm{kyr}$, the Lentia Complex formed between 24 and $15 \mathrm{kyr}$, the Fossa Caldera deposits and volcanic units emplaced between 15 and $8 \mathrm{kyr}$, the currently active La Fossa cone, and Vulcanello.

The short-wavelength, high-amplitude anomalies located in the center of «Piano Caldera» and in the center of «La Fossa Caldera» respectively lie along the SE-NW direction which is the main direction of the tectonic features of this region, parallel to the «Tindary Letojanni» Fault which develops more to the south in the northern part of Sicily. This orientation coincides with the direction of the migration of volcanism in the Island. Moving from south east of Vulcano to north west the volcanism becomes younger.

\section{Acknowledgements}

This work was supported by the European Commission, Contract ENV4-CT97-0697 «Electromagnetic and Potential Field Integrated Tomographies Applied to Volcanic Environments TOMAVE» and by the Austrian Science Founda- tion, contract P15515-TEC «Improved Modelling and Interpretation of Complex Geophysical Data Applied to the Eolian Volcanic Province» (COMVOLC). Additional financial support was given by the Geological Survey of Japan, by Istituto Nazionale di Geofisica e Vulcanologia, Dottorato di Ricerca in Geofisica - University of Bologna and the Austrian Exchange Service (ÖAD). We would further like to thank Maria Teresa Pareschi for providing the compilation of bathymetric data for the Eolian Islands.

\section{REFERENCES}

AgIP Spa (1981): Italia, Carta Magnetica - Anomalie del Campo Magnetico Residuo, scale 1:500000 (S. Donato Milanese, Italy).

Allan, T.D. and C. Morelli, (1971), A geophysical Study of the Mediterranean Sea, Boll. Geofis. Teor. Appl., XIII (50), 99-142.

Barberi, F., A. Giandino, A. Gioncada, P. LA Torre, A. SbranA and C. ZENuCCHINI (1994): The deep structure of the Aeolian Arc (Filicudi-Panarea-Vulcano Sector) in light of gravity, magnetic and volcanological data, $J$. Volcanol. Geotherm. Res., 61, 189-206.

Chiappini, M., A. Meloni, E. Boschi, O. Faggioni, N. BevERINI, C. CARMISCIANO and I. Marson (2000): Shaded relief magnetic anomaly map of Italy and surrounding marine areas, Ann. Geofis., 43 (5), 983-989.

De Astis, G., L. La Volpe, A. Peccirillo and L. Civetta (1997): Vulcanological and petrological evolution of Vulcano Island (Aeolian Arc, Southern Tyrrhenian Sea), J. Geophys. Res., 102 (B4), 8021-8050.

De Santis, A., L.R. Gaya-Piqué, G. Dominici, A. Meloni, J.M. TORTA and R. TozzI (2003): Italian geomagnetic reference field: update for 2000 and secular variation model up to 2005 by autoregressive forecasting, Ann. Geophys., 46 (3), 491-500.

Frazzetta, G., L. La Volpe and M.F. Sheridan (1983): Evolution of the Fossa Cone, Vulcano, J. Volcanol. Geotherm. Res., 17, 329-360.

Frazzetta, G., P.Y. Gillot, L. La Volpe and M.F. SherIDAN (1984): Volcanic hazards of Fossa of Vulcano: data from the last 6000 years, Bull. Volcanol., 47, 105-124.

Gabbianelli, G., C. Romagnoli, P.L. Rossi, N. Calanchi, F. LuCCHINI (1991): Submarine morphology and tectonics of Vulcano (Aeolian Islands, Southeastern Tyrrhenian Sea), Acta Vulcanol., 1, 135-141.

Molina, F. and A. De SAntis (1987): Consideration and proposal for a best utilisation of IGRF over areas including geomagnetic observatory, Phys. Earth Planet. Inter, 48, 379-385.

(received February 5, 2004; accepted November 10, 2004) 